JSPS Grants-in-Aid for Creative Scientific Research

Understanding Inflation Dynamics of the J apanese Economy

Working Paper Series No.10

\title{
Do Larger Firms Have More Interfirm Relationships?
}

\author{
Yukiko Umeno Saito \\ Tsutomu Watanabe \\ and \\ Mitsuru I wamura
}

March 29, 2007

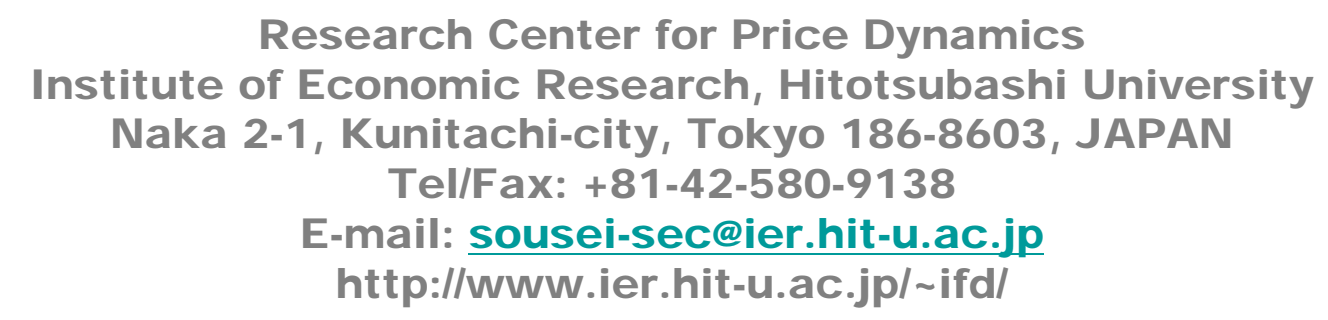




\title{
Do Larger Firms Have More Interfirm Relationships?
}

\author{
Yukiko Umeno Saito* \\ Fujitsu Research Institute
}

\author{
Tsutomu Watanabe \\ Hitotsubashi University
}

\author{
Mitsuru Iwamura \\ Waseda University
}

March 27, 2007

\begin{abstract}
In this study, we investigate interfirm networks by employing a unique dataset containing information on more than 800,000 Japanese firms, about half of all corporate firms currently operating in Japan. First, we find that the number of relationships, measured by the indegree, has a fat tail distribution, implying that there exist "hub" firms with a large number of relationships. Moreover, the indegree distribution for those hub firms also exhibits a fat tail, suggesting the existence of "super-hub" firms. Second, we find that larger firms tend to have more counterparts, but the relationship between firms' size and the number of their counterparts is not necessarily proportional; firms that already have a large number of counterparts tend to grow without proportionately expanding it.
\end{abstract}

Keywords: Network structure; interfirm relationships; hub firms; firm size; fat-tail distributions

\section{Introduction}

When examining interfirm networks, it comes as little surprise to find that larger firms tend to have more interfirm relatioships than smaller firms. For example, Toyota purchases intermediate products and raw materials from a large number of firms, located inside and outside the country, and sells final products to a large number of customers; it has close relationships with numerous commercial and investment banks; it also has a large number of affiliated firms. Somewhat surprisingly, however, we do not know much about the statistical relationship between the size of a firm and the number of its relationships. The main purpose of this paper is to take a closer look at the linkage between the two variables.

Such an exercise is useful to learn more about the evolution of firms' networks. Specifically, one may be interested in whether a large number of interfirm relationships is a necessary condition for a firm to grow rapidly. In a previous study on firms' growth [1], we found that firms successfully achieve continuous growth once their scale of production exceeds a certain threshold; otherwise, they are not able to achieve continuous growth. Based on this empirical finding, we suggested the hypothesis that whether a firm successfully builds a good and stable relationship with other firms and banks is the key to the firm's continuous growth.

*Corresponding author. Economic Research Center, Fujitsu Research Institute, 1-16-1 Kaigan, Minato-ku, Tokyo 105-0022, Japan. E-mail address: saito.yukiko@jp.fujitsu.com (Yukiko Umeno Saito) 
Interfirm networks have been investigated by several papers $[1,2,4,5]$. In particular, shareholding networks have been examined for those firms listed in the United States, Japan, and Italy [2,5], to find that these networks have scale-free characteristics, and that indegree exhibits power-law distributions. But these existing studies have only looked at a small subset of firms, typically listed firms or firms in a specific industry or region. In this paper, therefore, we look at 800,000 firms, covering about half of all corporate firms currently operating in Japan.

\section{Data}

The dataset we use is compiled by TOKYO SHOKO RESEARCH, LTD. (TSR). In this dataset, each firm reports three types of linkages with other firms: suppliers (i.e., firms from which it purchases raw materials and intermediate products, etc.); customers (i.e., firms to which it sells its products); and owners (i.e., firms by which it is owned). The maximum number of firms each firm reports in terms of each of the above three categories is twenty four and the dataset consequently contains about four millions relationships in total. The dataset also provides background information on each firm, such as its industry classification, region, sales, profits, and the year of establishment.

Table 1: Example of relationships

\begin{tabular}{lccccccc}
\hline & $\# 1$ & $\# 2$ & $\# 3$ & $\# 4$ & $\# 5$ & $\# 6$ & $\# 7$ \\
\hline Reporting firm & Firm A & Firm A & Firm A & Firm B & Firm B & Firm C & Firm D \\
Reported firm & Firm B & Firm C & Firm D & Firm A & Firm D & Firm D & Firm B \\
Type of relationship & supplier & supplier & customer & customer & supplier & supplier & customer \\
\hline
\end{tabular}

There are two different ways to count the number of relationships. One may count the number of firms which, say, firm A reports as its counterpart. We refer to this as the "outdegree." In the example presented in Table 1, the outdegree for firm A is 2 in terms of "supplier" relationships and 1 in terms of "customer" relationships, while the outdegree for firm B is 2 in total, and the corresponding number for firms C and D is 1, respectively. Note that it is highly possible that the outdegree is truncated at twenty four, simply reflecting the reporting rule set by the TSR.

Alternatively, one may count the number of firms which report firm A as their counterpart. We refer to this as the "indegree." In the example presented in Table 1, the indegree for firm A is 1 (i.e., firm B reports firm A as its customer), while the indegree for firm B is 2, and the corresponding numbers for firms $\mathrm{C}$ and $\mathrm{D}$ are 1 and 3, respectively. Note that the indegree could be truncated as well, given that the number of frims each firm reports as its counterpart is less than twenty four. But the bias caused by that would be smaller as compared with outdegree, so that indegree could be seen as a more accurate and reliable measure of the number of relationships.

\section{Network structure}

We investigate the network structure in terms of the indegree distribution. Specifically, we first look at its unconditional distribution, then proceed to the distribution for a subgroup of firms that are identified as "hub" firms, and finally look at the distribution conditional on firms' scale of production/sales. 


\section{[Insert Figure 1]}

Figure 1 shows three kinds of indegree distribution, namely, the cumulative density function (CDF) of the indegree in terms of "supplier" relationships, the CDF in terms of "customers" relationships, and the CDF in terms of "owner" relationships. As can be clearly seen in the figure, each of the three distributions exhibits a fat tail and, more interestingly, each line has an almost identical slope. The reference line shown in the figure represents the slope associated with the power-law distribution whose cumulative density function is given by $R(x)=x^{-(\alpha-1)}$ with $\alpha=2.3$. A simple comparison with the reference line indicates that each of the three obeys a power-law distribution with $\alpha=2.3$, implying that the indegree is concentrated on a small number of firms.

\section{[Insert Figure 2]}

Firms with a large number of relationships may be regarded as "hub" firms. Given this interpretation, we are interested in the network among these hub firms. We define firms with an indegree greater than $N(N=50,100,200,500$, and 1000) as hub firms and then count the indegree among these hub firms. Note that we sum up all of the three relationships (namely, "suppliers," "customers," and "owners") in this exercise. Figure 2 shows the result of this exercise. Again, we see that each distribution exhibits a fat tail and that each distribution has an almost identical slope. This result suggests the existence of a layered structure in firms' networks; that is, among the hub firms, there are "super-hub" firms.

\section{Firms' size and the number of their relationships}

Figure 3 shows the CDF for firms' size. Here, we measure firms' size by their sales. As can be seen in the figure, the CDF is again fairly close to a power-law distribution, implying that a small number of firms in the top group occupy a disproportionately large share of total sales. However, if one compares Figures 1 and 3, one can see that the firm-size distribution has a fatter tail than the indegree distributions, suggesting that the degree of concentration is weaker for firm size than for network. In fact, the parameter $\alpha$ is now about 2.0, substantially smaller than in the case of the indegree distributions.

\section{[Insert Figure 3]}

In Figures 4 and 5, we take a closer look at the relationship between firms' size and the number of their relationships. Figure 4 shows the indegree distributions for four subgroups identified by firm size. This conditional distribution shows that firms with larger sales tend to display a greater indegree. At the same time, Figure 4 does not necessarily indicate a linear relationship between the two variables. To find out more about the relationship between the two variables, we calculate the points at which the CDF of the indegree distribution equals $1 / 2,1 / 4$, and $1 / 8$ for each of ten subgroups identified by firm size. The result of this exercise is presented in Figure 5. We see that the points associated with $1 / 2$ (namely, the median of the distributions) are almost parallel to the linear reference line, implying that the relationship between the two is indeed a proportional one as far as the median is concerned. However, we also see that the points associated with $1 / 4$ and $1 / 8$ are not parallel to the linear reference line, but are significantly flatter than the reference line. This indicates that firms that have already have a large number of realtioships do not necessarily increase it even when they grow in terms of sales. 
[Insert Figures 4 and 5]

One may wonder why firms with a large number of relationships do not proportionately increase it as they grow. One possibility is that those firms may want to save on the "maintenance costs" of their networks. For example, several studies on the costs and benefits of bank-firm networks [4] have shown that multiple relationships with banks (namely, a firm has deposit/borrowing relationships with more than one bank) are beneficial to firms since they reduce the risk of a liquidity shortage due to bank failure. However, such relationships are not free; firms have to pay maintenance costs in the form of, say, preparing reporting documents to multiple banks. Given such costs, firms typically choose not to monotonically increase the number of banks with which they have transactions even as they become larger in terms of sales/production. This is easy to see if one considers, for example, that the number of banks Toyota has transaction with is approximately the same as the corresponding number for much smaller firms. Generally speaking, it would be costly for firms to maintain their interfirm relationships, and if this is the case, firms that have already a large number of relationships may choose not to expand their relationships even as they grow. ${ }^{1}$

\section{Conclusion}

We have found in this paper that larger firms tend to have more interfirm relationships, but the relationship between firms' size and the number of their counterparts is not necessarily proportional; firms that already have a large number of counterparts tend to grow without proportionately expanding it. The next step in this line of investigation would be examine more carefully the causality running between firms' size and the size of their networks, i.e., whether a large network is a cause or just a result of a larger scale of production. Also, it would be an interesting task to investigate other aspects of interfirm network, including clustering index and mean distance. We leave these topics to our future work.

\section{Acknowledgement}

We would like to thank the Research Institute of Economy, Trade and Industry (RIETI) for allowing us to use the TSR data. We also would like to thank Hideki Takayasu, Iichiro Uesugi, and the members of the research group on corporate finance at the RIETI, for useful comments.

\section{References}

[1] Caldarelli G., Garlaschelli D. and Battiston S. (2006), "The Skelton of the Shareholders Networks," H. Takayasu (ed.), Practical Fruits of Econophysics, Tokyo: Springer-Verlag, 297-300.

[2] Garlaschelli D., Battiston S., Castri M, Servedio V.D.P. and Caldarelli G. (2005), "The Scale Free Nature of Market Investment Network," Physica A 350, 491-499.

[3] Saito, Y., T. Watanabe, M. Iwamura (2006), "Path-Dependency of Firm Growth," Bussei Kenkyu, Vol. 86, No. 4, in Japanese.

\footnotetext{
${ }^{1}$ Another possibility is that firms with a large number of relationships may become hub firms or even super-hub firms, thereby saving on the number of spokes (namely, the indegree) they directly have with other firms.
} 
[4] Souma, W., Y. Fujiwara, H. Aoyama (2005), "Shareholding Networks in Japan," http://arxiv.org/abs/physics/0503177.

[5] Souma, W., Y. Fujiwara, H. Aoyama (2006), "Change of Ownership Networks in Japan," in H. Takayasu (ed.), Practical Fruits of Econophysics, Tokyo: Springer-Verlag, 307-11.

[6] Detragiache, E., P. G. Garellia, L. Guiso (2000), "Multiple versus Single Banking Relationships: Theory and Evidence," Journal of Finance 55(3), 1133-1161. 


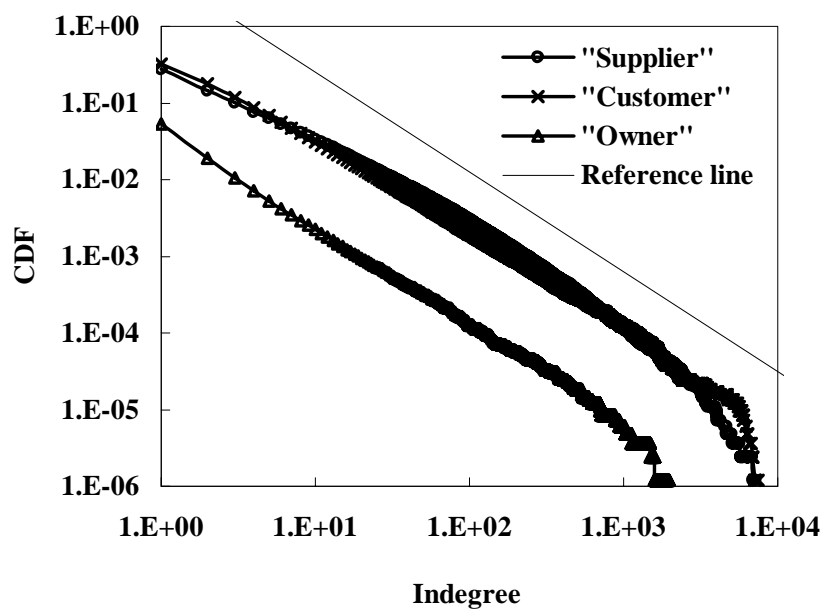

Figure 1: Indegree distributions in log-log plot. Open circles, cross symbols, and open triangles represent "suppliers", "customers", and "owners" relationships, respectively. The solid line represents a reference line for the power-law distribution whose cumulative density function is given by $R(x)=$ $x^{-(\alpha-1)}$ with $\alpha=2.3$.

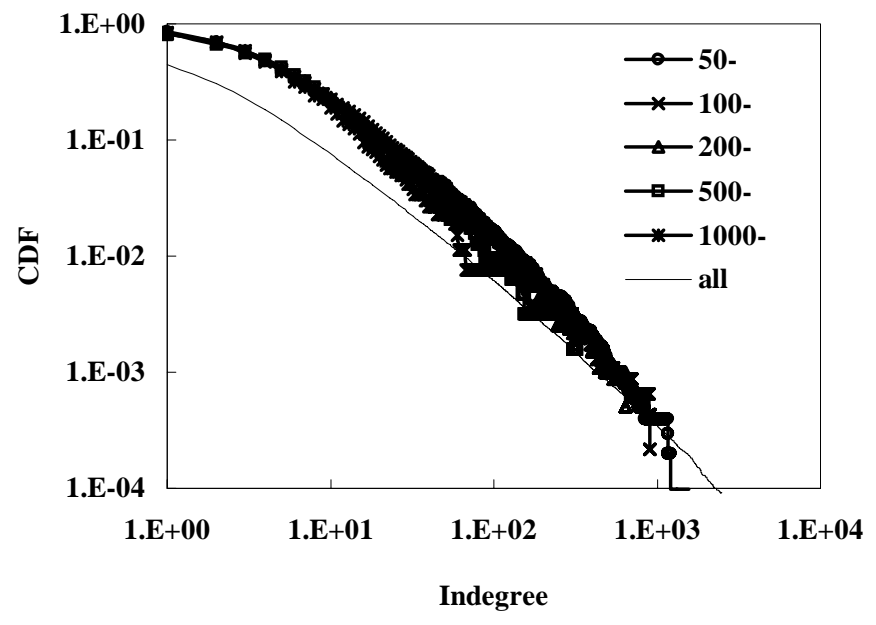

Figure 2: Indegree distributions for hub firms. Each represents a distribution for hub firms with an indegree greater than 50,100, 200, 500, and 1000 . 


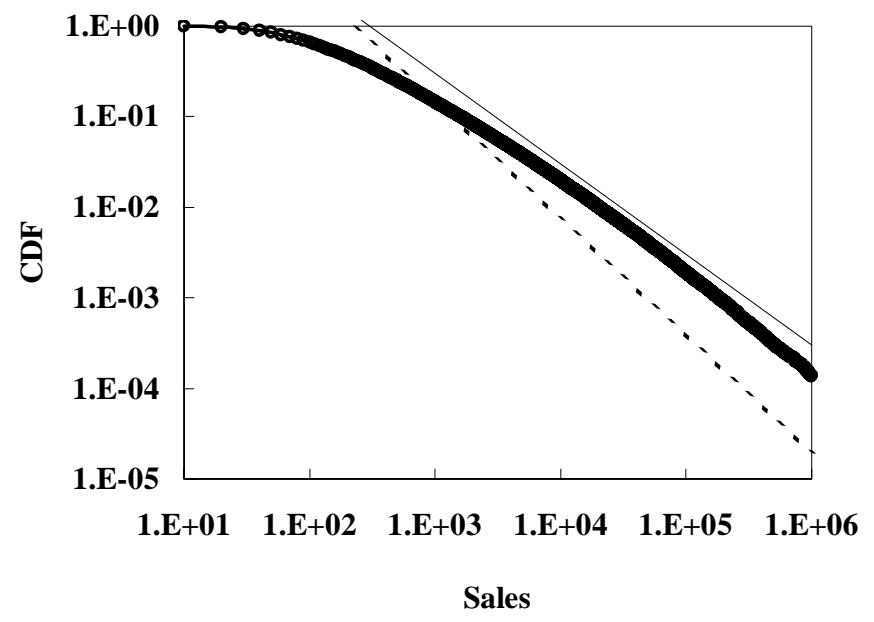

Figure 3: Distribution of firms' sales in log-log plot. The solid and dotted lines represents reference lines for the power-law distributions whose cumulative density function is given by $R(x)=x^{-(\alpha-1)}$ with $\alpha=2.0$ and $\alpha=2.3$, respectively.

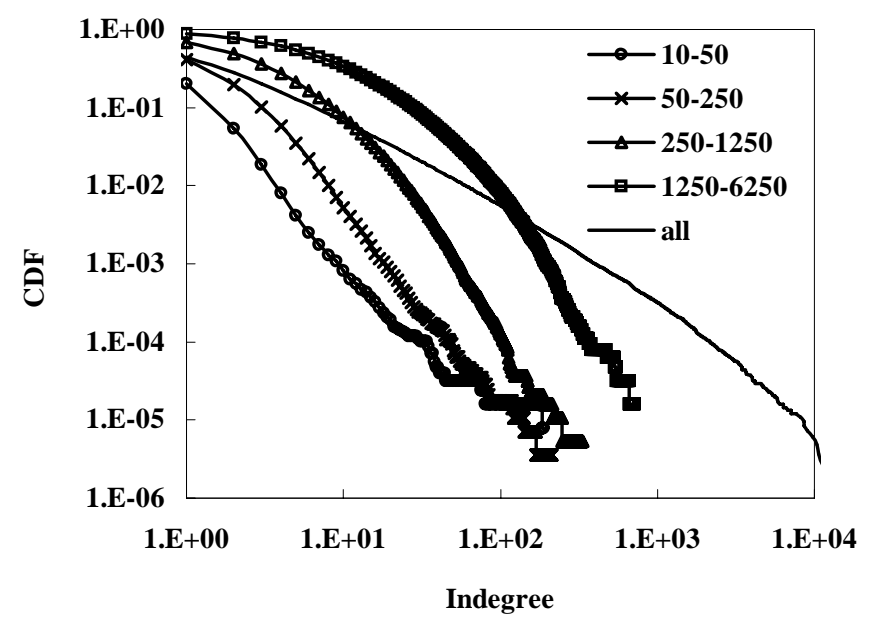

Figure 4: Indegree distributions conditional on firms' sales. The entire sample is divided into four sub-groups identified by sales. 


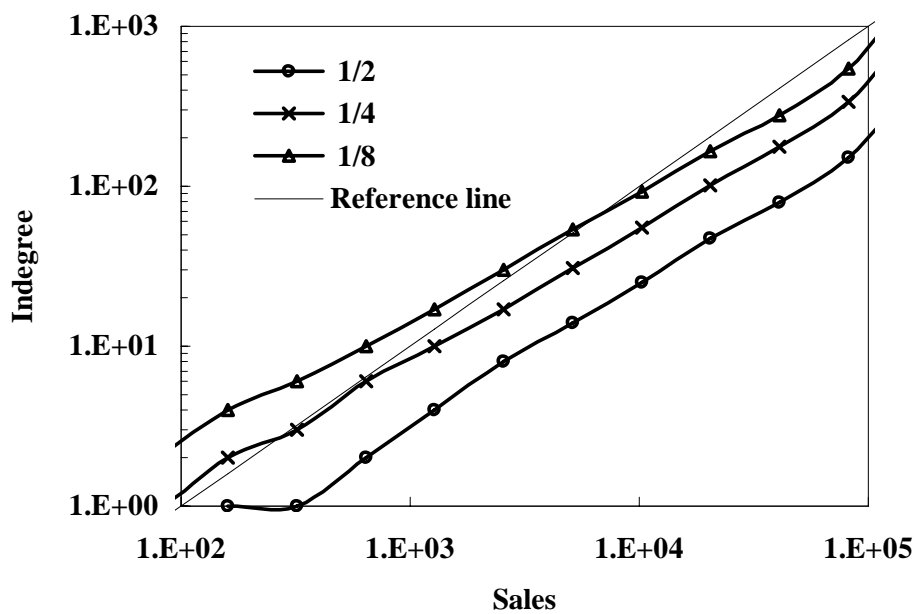

Figure 5: Sales versus indegree. The figure shows the points at which the CDF of the indegree distribution equals $1 / 2,1 / 4$, and $1 / 8$ for each of ten subgroups identified by firm size. 